Spectrographic Analysis", ASTM Special Technical Publication, No. 157, p. 43 (1953), (A. S. T. M.).

5) G. E. Noakes : ibid., p. 57.

6) H. J. Beattie, R. M. Brissey : Anal. Chem., 26, 980 (1954).

7) E. Gillan, H. T. Heal : Brit. J. Appl. Phys., 3, 353 (1952).

8) K. Sagel : “Tabellen zur Rōntogenstructuranalyse”, p. 123 (1953), (Springer-Verlag, Berlin).

9) K. Sagel : Tabellen zur Röntogn-Emissionund Absorpion-Analyse", p. 54 (1959), (Springer Verlag, Berlin).

10) N. Spielberg : Philips Research Reports, 14, 215 (1959).

11）日本金属学会編 : “金属便覧”, p. 866 (1960).

$$
\text { is }
$$

Determination of copper and nickel. (X-ray fluorescence analysis of copper-nickel alloy. I.) Tsutomu Furasawa*, Tsugio TAKEUCH ${ }^{*}$ and Akinari ICHIRYU** (* Institute of Techno-analytical Chemistry, Faculty of Engineering, Nagoya University and **Sumitomo Light Metal Industries, Co.)

Non-destructive X-ray fluorescence analysis of copper-nickel alloy for $\mathrm{Cu}$ and $\mathrm{Ni}$ was studied. The spectrum of $\mathrm{CuK} \alpha$ or $\mathrm{NiK} \alpha$ was recorded on a chart, and the intensity of the spectrum was measured as the peak height, followed by a necessary correction with the corresponding spectrum on the standard sample. Variation of the primary-ray intensity did not give any significant effect for corrected intensity. The working line obtained by plotting $I_{\mathrm{CuKa}}$ on $\mathrm{Cu} \%$ was straight, but the line for $I_{\mathrm{NiK} \alpha}$ on $\mathrm{Ni} \%$ was a convex curve. The cause of these characteristics of working line was discussed.

Correction for iron content was needed in case of determination of nickel in monel metal which contained higher quantities of iron. The other minor elements did not interfere. The main error was apt to come from the intensity measurement itself, and the standard deviation $(\sigma)$ was $0.5 \%$ for both $\mathrm{Cu}$ and $\mathrm{Ni}$ when the intensity measurement was carried out on a cutting face by lathe. It seemed that finishing of the surface of specimen should follow the regular course, because the state of the surface was very much improved by means of simple finishing by sandpaper, by which the variation of the corrected intensity was reduced.

(Received Mar. 31, 1961)

\title{
銅-ニッケル合金中のコバルトおよび鉄の螢光 $\mathbf{X}$ 線分析*
}

\author{
深 沢 力, 武内 次夫**, 一柳 昭成***
}

\begin{abstract}
記録法により実跧し,検量線はいずれも螢光X線強度一含有量の関係で示した. コバルトの定量 : 白銅 の場合と洋白の場合とでは别々の検量線が必要であった。白銅は $0.06 \sim 0.34 \%$ のコバルトを $\sigma=0.006$ $\%$ 程度の精度で簡便に定量できた。，洋白は銅含有量の差異による影響が大きく，銅含有量の同じもの でとに検量線を作成しておく必要があった，鉄の定量：白銅，洋白とも同一の検量線で定量でき，0.4 $\sim 3.3 \%$ の鉄を $\sigma=0.04 \% ， 0.14 \%$ 以下の鉄でも $\sigma<0.005 \%$ 程度の精度で迅速簡易に定量できた。 記録法に上る定量限界はコバルト，鉄とも0.01〜0.005\% 程度であった。
\end{abstract}

前報1において銅ーニッケル合金の主成分である銅, 二 ッケルの非破壊分析について述べた. 今回は微量成分で あるコバルト抢よび鉄の非破壊分析について述べる．試 料および装置は一切前報と同じであった。

螢光X線分析の際強度測定は多くは計数法によってい るようであるが，X線スペクトルを記録紙に記録させて

* 銅ーニッケル合金の螢光 $\mathrm{X}$ 線分析（第 2 報）

** 名古屋大学工学部工業分析化学教室 : 名古屋市千種 区不老町

*** 住友軽金属工業株式会社 : 名古屋市港区干年口ノ割
そのピークの高さより強度を求める記録法るつぎのよう な利点, または特徴をもっていると思われる. 測定結果 をそのまま保存でき，試料によるバックグラウンドの強 さやその形の違い，実験中の装置の異常など発見しやす W.

また，強度の読み取りに間違いがあっても読み直しが 可能であり, 計数法より気軽に実験できるように思われ る.したがって記録法によって検討し, 定量の際の種々 な問題点, 精度などを明らかにするとともに記録法の適 用限界などを知ることとした。 


\section{1 コバルトの定量}

通常白銅，洋白などの 銅-ニッケル合金中にはコバル トが 0.06〜0.6\% 程度含まれているのでこの範囲につい て検討した。管球電圧および電流をそれぞれ $35 \mathrm{kV}, 20$ $\mathrm{mA}$ とし, Sf : $8 \times 4$ (すなわち波高分析器の Sf : 8 , レ 一トメーターの Sf: 4), m: 1 , t. c. $: 4 \mathrm{sec}$, 波高分析 器はスナップスイッチを Int. の側に倒して用いた. 微 量成分の分析であるから十分強い螢光 $\mathrm{X}$ 線をうるため, 試料の一次 X 線被照射面はできるだけ広い方が望まし い. したがって, 試料の一次 $\mathrm{X}$ 線被照射面積を特別に制 限するためのマスク2 はしなかった. その他の条件は特 記しない限り前報と同じであった. 検量線作成のために 䖝光 $\mathrm{X}$ 線分析した一例を Fig. 1 に示した.

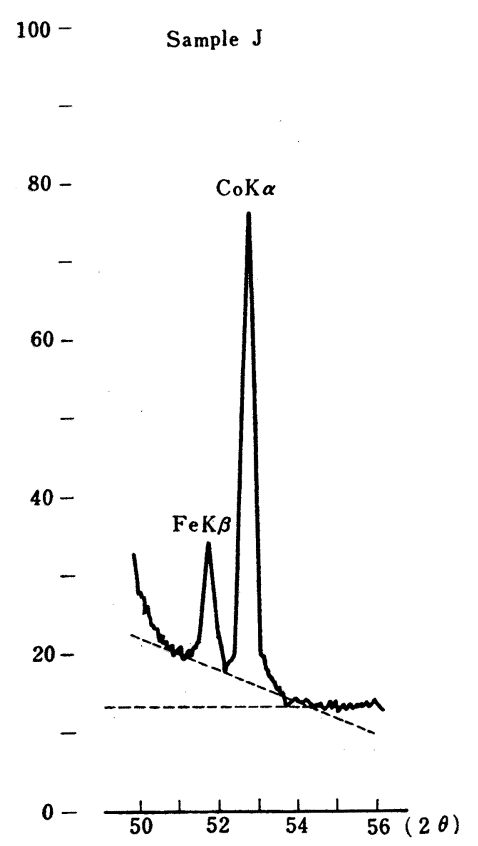

Fig. 1 Spectrum of $\operatorname{CoK} \alpha$ line

\section{$1 \cdot 1$ 強度の測定}

$\mathrm{CoK} \alpha$ 線強度は記録紙上で $\mathrm{CoK} \alpha$ 線のピークの高さ からバックグラウンドを差引いたものを記録紙の目盛数 で表わした. バックグラウンドは斜または水平にとる方 法が考えられる. バックグラウンドがこの部分で傾斜し ているのは $\mathrm{NiK} \boldsymbol{\alpha}$ 線が非常に強く, そのピークの裾の 一部が $\mathrm{FeK} \beta$ 線とともに $\mathrm{CoK} \alpha$ 線のピークと重ってい ることに基づく.したがって, バックグラウンドを水平 にとって $\mathrm{CoK} \alpha$ 線強度を求めると真のものより大にな
り， NiK $\boldsymbol{\alpha}$ 線強度（すなわちニッケル含有量）の差異に よる影響も大きいのではないかと思秃れたこのような 理由から両方法により強度測定を行ない，その絬果を比 較した。

強度補正も前報と同梯なっ法によることとし，コバル 卜含有量の多い試料 $\mathrm{K} の \operatorname{CoK} \alpha$ 線強度を標準にした。

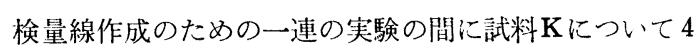
回䖝光 $\mathrm{X}$ 線分析したが，その $\mathrm{CoK} \boldsymbol{\alpha}$ 線強度は (バック グラウンドを水平にとった場合） $61.2 \sim 59.5$ (目盛) で 差は 1.7 (目盛)であった。これ溦量成分の分析とし ては十分な精度と考元られたので, 一次 X線強度の変動 もなく, 装置も安定していたものとして強度補正省い た.

\section{$1 \cdot 2$ 検量線および定量の精度}

バックグラウンドを水平あるいは斜にとって $\mathrm{CoK} \alpha$ 線強度を求め, 検量線を作成した結果は Fig. 2 の上う であった．両方の場合ともコバルト含有量 $0.35 \%$ 以下 のものは一つの直線上にのったが，それ以上はこの直線 にのらなかった. コバルト含有量が $0.35 \%$ 以下のもの は白銅で，それ以上のものは洋白であった.したがって 白銅の分析と洋白の分析とに分けて述べる.

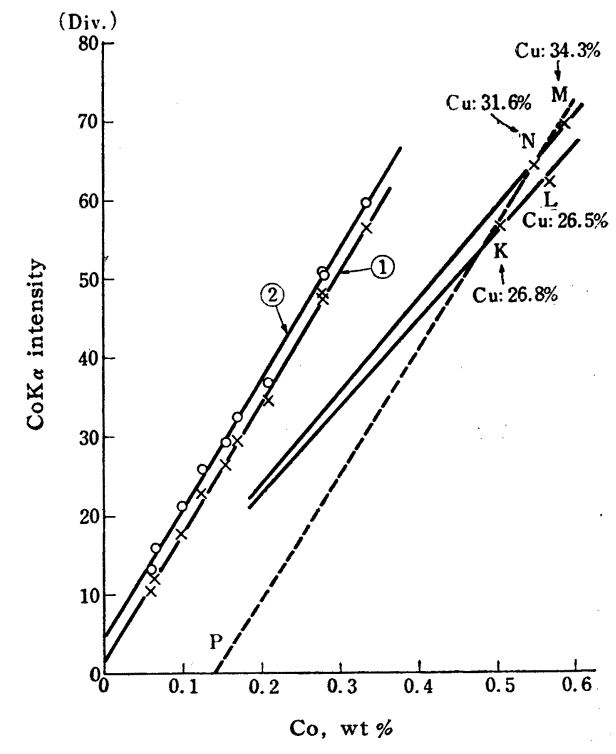

Fig. 2 Calibration curves for Co 100 Div. $=1,600 \mathrm{cps}$

$\times$ Intensity obtained by subtraction of back ground (inclined) from peak height

$O$ Intensity obtained by subtraction of back ground (horizontal) from peak height 


\section{$1 \cdot 2 \cdot 1$ 白銅中のコバルトの定量 この場合測定俌} 汇一つの直線にのったので $\operatorname{CoK} \alpha$ 線強度を $y$ 軸, コバ ルト含有量を $x$ 軸として最小二乘法により回㷌直線を求 め, 各点のこの直線からのバラッキを求めた。

(1) バックグラウンドを斜にとった場合 $y=164.0 x+1.38, \sigma_{y}=1.01$ (目盛),$\sigma_{x}=0.006 \%$ Co

(2) バックグラウンドを水平にとった場合

$y=163.6 x+4.23, \sigma_{y}=1.26$ (目盛),$\sigma_{x}=0.008 \% \mathrm{Co}$

両検量線は大体平行でバラッキも大差なく, $0.35 \%$ 以 下のコバルトを $\sigma=0.006 \sim 0.008 \%$ 程度で定量できる ことを示した。 また $\mathrm{NiK} \alpha$ 線強度の差異による影響も 少ないことがわかった。

\section{$1 \cdot 2 \cdot 2$ 洋白中のコバルトの定量 コバルト含有量} の多い部分では $1 \cdot 2 \cdot 1$ に述べた検量線に全く一致せず, 一見 $\mathrm{K}, \mathrm{M}, \mathrm{N}$ などの試料は別の系統の一つの検量線 (Fig. 2 に点線で示した) に属し，Lのみが大きく偏っ ているかのように思えた.しかしながらK, N,Mなどが 一つの検量線に属しているということにすると，この検 量線は原点よりはるかに離れた $x$ 軸上の $\mathbf{P}$ 点を通るので 理解できない. ニッケル含有割合の多い合金でコバルト 含有量が $0.5 \%$ 以下の試料を準備できず十分な実験的証 “明はできなかったが，つぎのような考え方が妥当ではな いかと思われる.

一定のマトリックス中の微量の元素の螢光 $\mathbf{X}$ 線分析に おいては, 種々の波長の $\mathrm{X}$ 線に対する吸収の条件, 定量 元素の励起に関する条件など常に一定である. したがっ $\tau$, 螢光 $\mathrm{X}$ 線強度と元素の含有量との間に注線関係が 成り立つものと思われる*. しかもバックグラウンドを 正しく差引き, 真の䖝光 $\mathrm{X}$ 線強度によって検量線を作成 するならば，その検量線は原点を通るはずである。この 場合, $\mathrm{X}$ 線分析に扔いて問題になるマトリックスの成分 は主成分である銅およびニッヶルである.したがって，

Fig. 2 において銅含有量のほとえど等しい試料 $\mathrm{K}, \mathrm{L}$ および $\mathrm{N}, \mathrm{M}$ などの測定值を結ぶと, それぞれ原点を通 る一つの直線上にほぼのっていることがわかる。すなわ ち, 洋白中のコバルトを定量する場合は，銅またはニッ ケルの含有割合によって $\operatorname{CoK} \alpha$ 線の強度が影響を受け る.したがって,銅またはニッケルの含有量による補正， または銅ーニッヶルの割合の異なるものごとに検量線を 作成しておく必要があることを示しているものと思われ る.

なお，銅含有量の少ないものほど CoK $\alpha$ 線の強度は 弱いが，このような現象についてはつぎのように説明で きる.

\footnotetext{
*文献 1) の (1) 式, (2) 式およびその理論参照.
}

$\operatorname{CuK} \alpha$ 線の波長は $\mathrm{CoK}$ 吸収端よりも短くこれに近 い**. したがって, $\mathrm{CuK} \alpha$ 線はコバルトを励起し, $\operatorname{CoK} \alpha$ 線に対し強調効果を示す. $\mathrm{NiK} \beta$ 線も同様な理由によっ て $\operatorname{CoK} \alpha$ 線に対し強調効果を示す. しかしながら, コ バルトの $\mathrm{CuK} \alpha$ 線打よび $\mathrm{NiK} \beta$ 線に対する吸收係数, $\mathrm{CuK} \alpha$ 線および $\mathrm{NiK} \beta$ 線の強度などを考え比較すると, $\operatorname{CuK} \alpha$ 線による強調効果の方がはるかに大きいと考え られる.このような理由から, 銅：ニッケル比が变化し た場合, $\mathrm{CuK} \alpha$ 線による強調効果の減少は $\mathrm{NiK} \beta$ 線によ る強調効果の増加により多少は補われはするが, $\mathrm{CuK} \alpha$ 線による強調効果の変化または相違が $\operatorname{CoK} \alpha$ 線強度に 強く影響を与えるのではないかと思われる. さらに，コ バルトの $\mathrm{K}$ 励起は WL $\alpha_{1}$ 線によっても行なわれるが, 二 ッケルの WL $\alpha_{1}$ 線に対する吸収係数はきわわて大きい はずである.したがって，ニッケル含有量の多いものほ ぞ $\mathrm{WL} \alpha_{1}$ 線による励起は減少するので $\operatorname{CoK} \alpha$ 線強度は 弱くなる.

なお，白銅中のコバルトの定量の場合は，以上に述べ たような銅含有量の差異による影響が現われていなかっ た.これは白銅中の銅含有量がきわめて大きいので, 洋 白のときのように銅含有量の差異が鋭敏に影響しないの かも知れない。

\section{3 本法によるコバルトの定量限界}

$1 \cdot 2 \cdot 1$ において求めた回帰直線からの各点のバラッキ は, バックグラウンドを斜にとった場合 $\sigma_{x}=0.006 \% \mathrm{Co}$ であった. このバラツキを極微量のコバルトの定量に際 して可能な強度測定の最もよい精度と考え, 定量限界を $3 \sigma$ とするならば，本法のような記録法による定量限界 は 0.018\% Co となる. しかしながら， $\sigma_{x}=0.006 \%$ は 後述 $2 \cdot 2$ の鉄の定量のように, 特に微量のものを分析 して得た值ではないので, そのまま定量限界の根拠とす るには適さない.コバルト含有量の最も少なかった試料 $\mathrm{H}(\mathrm{Co}: 0.062 \%)$ について螢光X線分析した結果(Fig. 3-a ), $2 \cdot 3$ に述べる鉄の定量限界に対する考察なども比 較して検討すると, コバルトの場合も鉄と同程度の微量 まで本法によって迅速簡便に定量できるものと思わ机 る.すなわち管球電圧, 電流を多少変えてもバックグラ ウンド対ピークの関係はあまり変わらないので, 本法に よるコバルトの定量限界は 0.01 0.005\% 程度と思われ る.

なお, Fig. 3-b に試料Hについて波高分析して䖝光 X線分析した場合を示した. Fig. 3 において $\mathrm{a}$ とをを 比較すると, 波高分析した場合バックグラウンドの減少

\footnotetext{
** 文献 1) の Fig. 5 参照.
} 
率は約 1/10 程度であり, 波高分析の効果はきわめて少 なかった. したがって, 波高分析器の条件の選定のわず らわしさなどを考光るならば，分析法としては波高分析 しない方が簡便でよいように思われた。

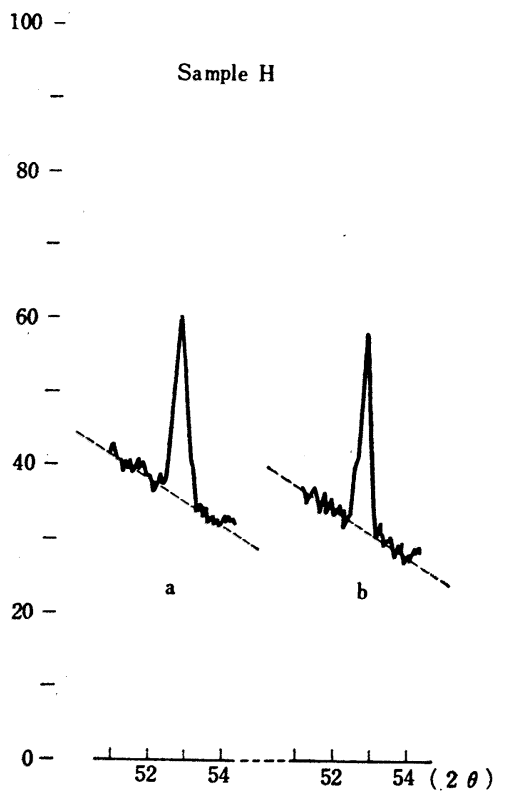

Fig. 3 Effect of pulse height discrimination Co : $0.062 \% ; 35 \mathrm{kV}, 20 \mathrm{~mA} ;$ Sf $: 8 \times 2 ;$ t. c. $: 2 \mathrm{sec}$ a : Without pulse height discrimination b : With pulse height discrimination

\section{2 鉄の定量}

白銅，洋白などの銅ーニッケル合金中には鉄が 0.02 $3 \%$ も含まれている場合がある。したがって $0.2 〜 3 \%$ 程度と, $0.14 \%$ 以下の鉄を定量する場合について検量線 を作成して検討した。

\section{$2 \cdot 1 \quad 0.2 \sim 3 \%$ 程度の鉄の定量}

管球電圧および電流をとれぞれ $35 \mathrm{kV}, 20 \mathrm{~mA}$ とし， 波高分析はせず Sf: $8 \times 16, \mathrm{~m}: 1$, t. c. : $2 \mathrm{sec}$ として 䖝光X線分析した. またコバルトの定量の場合と同様に 試料の一次 $\mathrm{X}$ 線被照射面積を制限するためのマスクをせ ず，その他の条件も特記しない限り前節コバルトの定量 の場合と同じであった. 螢光X線分析結果を Fig. 4 に 示した.

強度測定法も前節コバルトの定量の場合と同じであ り, この場合も一連の実験中一次 $\mathrm{X}$ 線強度も比較的安定 しており, 微量成分の定量でもあるので, 強度補正を行
なわなかった。

検量線を Fig. 5 に示した. 検量線は直線であると仮 定して $\mathrm{FeK} \alpha$ 線強度を $y$ 軸, 鉄の含有量を $x$ 軸として 回帰直線を求め, その直線よりの各点の偏差を求めた. その結果はつぎのようであった。

$y=21.60 x+1.18, \sigma_{y}=0.89$ (目盛),$\sigma_{x}=0.041 \% \mathrm{Fe}$

80 -

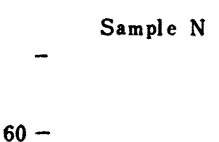

$60-$

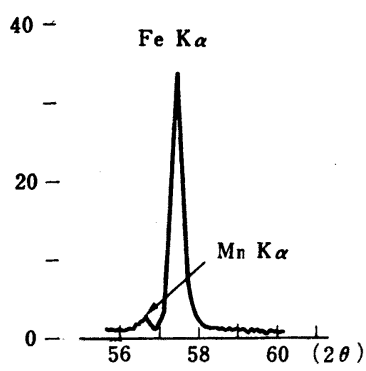

Fig. 4 Spectrum of $\mathrm{FeK} \alpha$ line Fe : $1.42 \% ; 35 \mathrm{kV}, 20 \mathrm{~mA}$; Sf : $8 \times 16 ;$ t. c. : 2 sec

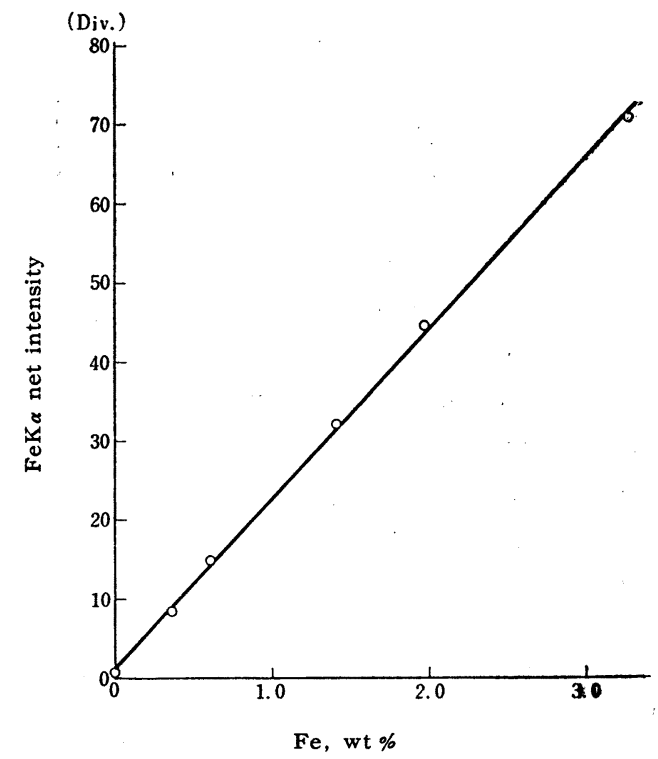

Fig. 5 Calibration curve for $\mathrm{Fe}(<3 \%)$. 100 Div. $=6,400 \mathrm{cps}$ 
すなわち，この場合は特別に障害になるような問題も なく，白銅，洋白を 通じ銅ーニッケル合金中の鉄を一う の検量線で，化学分析と同程度の精度で迅速簡便に定量 できた.

\section{$2.20 .14 \%$ 以下の鉄の定量}

この場合は $\mathrm{FeK} \boldsymbol{\alpha}$ 線に対する波高分布曲線を求め, その半価幅 $(\mathrm{W})$ の約 2 倍 $(2 \mathrm{~W})$ を window 幅とし, 被高分布曲線に対し対照的に window をセットアして 波高分析した ( $\mathrm{FeK} \boldsymbol{\alpha}$ 線によってカウンター内に生じた パルスの $90 \%$ 以上を計数する条件)). 強度のきわめて 弱いX線を測定するのであるから scale factor を $1 \times$ 16 または $1 \times 8$ としてピークを記録させた. 強度補正し た場合はすべて scale factor : $1 \times 16$ の場合の目盛数に 換算し, 強度補正しない場合は図示した場合わかりやす いように scale factor $1 \times 8$ に換算して表わした. また 微量成分の分析であるので多少精度を悪くしても迅速簡 便に分析することを考元，ゴニオメータ一の走査速度を $2 \theta=2 \% / \min$ とした場合について検討した. その他の条 件は $2 \cdot 1$ と同じであった.

scale factor を $1 \times 16$ または $1 \times 8$ として䖝光 $\mathrm{X}$ 線 分析した例を Fig. 6 に示した. scale factor を小さ くしたのでジッターは大きくなり, バックグラウンドの 強度は $2 \theta$ とともに次第に变化した. したがって, バッ クグラウンドを Fig. 6 の点線のようにジッターの中央 を通る直線とし, $\mathrm{FeK} \alpha$ ピークの先端の高さより差引い たものを $\mathrm{FeK} \boldsymbol{\alpha}$ 線強度とした. 検量線作成のための一 連の実験中, 試料 I を強度補正のための標準として各試 料の間に入れ 6 回螢光 $\mathrm{X}$ 線分析した. その際の試料 I の $\mathrm{FeK} \boldsymbol{\alpha}$ 線強度の測定結果はつぎのようであった。

$\mathrm{FeK} \alpha$ 線強度の平均值 $\left(\bar{I}_{\mathrm{Fe}}\right)=62.57$ (目盛), 標準偏 差 $(\sigma)=1.11$, 標準偏差の相対値 $\left(\varepsilon=\sigma / \bar{I}_{\mathrm{Fe}}\right)=1.8 \%$ 試料 I $\mathrm{FeK} \alpha$ 線強度により強度補正した場合 i) と, しない場合 ii) について検量線を作成した結果は Fig. 7 のようであった.

両検量線について $\mathrm{FeK} \boldsymbol{\alpha}$ 線強度を $y$ 軸とし, 鉄含有 量(平均值)を $x$ 軸として回帰直線を求め, その直線より の各点のバラッキを求めた結果はつぎのようであった。

i) $y=4170 x+8.45, \sigma_{y}=1.96$ (目盛), $\sigma_{x}=0.004_{7} \% \mathrm{Fe}$

ii) $y=5230 x+10.59, \sigma_{y}=2.54$ (目盛), $\sigma_{x}=0.004_{9} \% \mathrm{Fe}$

i) の場合測定值は $I_{\mathrm{Fe}}=14 \sim 63$ (目盛) の範囲でその 平均值 $\bar{I}_{\mathrm{Fe}}=31.85$ に対し $\sigma_{y}=1.96$, すなわち $\varepsilon=6.2$ $\%$, ii) の場合 $I_{\mathrm{Fe}}=17 \sim 80$ (目盛), $\bar{I}_{\mathrm{Fe}}=39.91$ 亿対し $\sigma_{y}=2.54, \varepsilon=6.4 \%$ であって, 試料 $\mathrm{I} の \bar{I}_{\mathrm{Fe}}=62.57$,

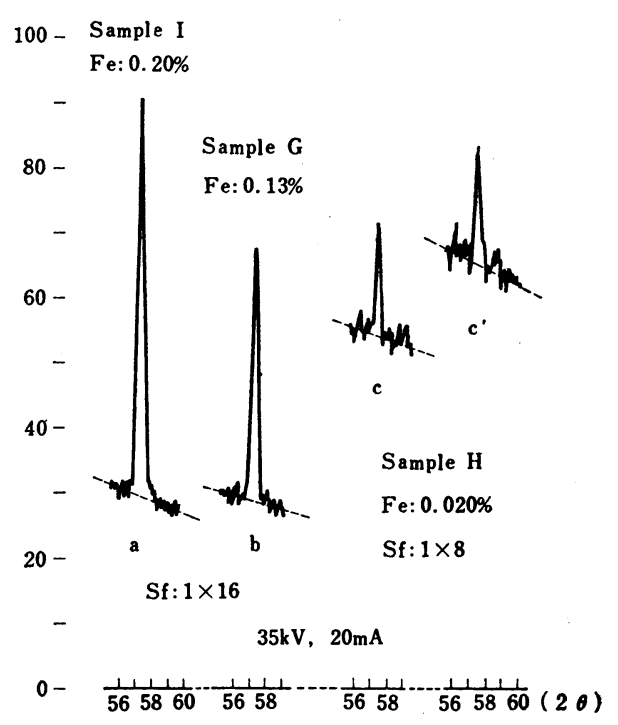

Fig. 6 Spectrum of $\mathrm{FeK} \alpha$ line and effect of pulse height discrimination

$a, b, c:$ With pulse height discrimination - c': Without pulse height discrimination

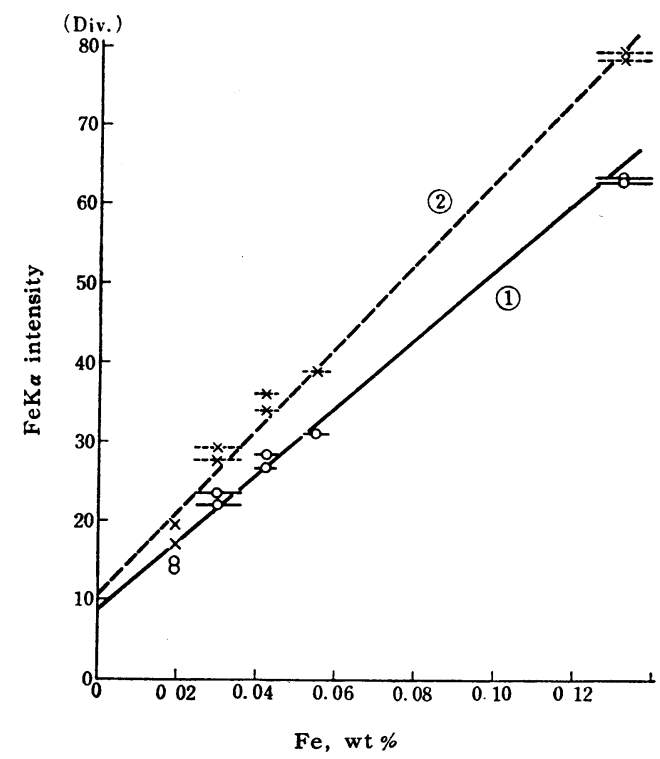

Fig. 7 Calibration curves for $\mathrm{Fe}(<0.13 \%)$

$\times, \bigcirc$ Mean value obtained by chemical analyses (1) $100 \mathrm{Div} .=800 \mathrm{cps}$, Intensity was corrected.

(2) $100 \mathrm{Div} .=400 \mathrm{cps}$, Intensity was not corrected.

$\varepsilon=1.8 \%$ に比ベバラツキはきわめて大きい. また, 検 量線はほぼ原点を通るべきものと思われるが通っていな い.これらは前報》 Table I からも明らかなように化 
学分析結果のバラッキが特に大きいこと，またカタヨリ があることなどによるものと思われる。

\section{$2 \cdot 3$ 本法による鉄の定量限界}

鉄含有量の最も少なかつた試料 $\mathrm{H}(0.020 \% \mathrm{Fe})$ につ いて，2・2で述べた条件で䖝光X線分析した結果は Fig. 6-cのようであった. $2 \cdot 2$ において求めた回帰直線から の各点のバラツキ $\sigma_{x}=0.005 \% \mathrm{Fe}$ から定量限界を $3 \sigma$ と考えるならば, 本法による鉄の定量限界は $0.015 \% \mathrm{Fe}$ となるが，0.005\% Fe 程度の存在は確認できる。 また $\sigma_{x}=0.005 \% \mathrm{Fe}$ には化学分析のバラツキも影響してい ること它考元ると，鉄の定量限界は $0.01 〜 0.005 \%$ と思 われる。

なお，Fig. 6-c'に試料 Hについて波高分析しないで 䖝光 $\mathrm{X}$ 線分析した場合を示したが，波高分析した場合 $\mathrm{c}$ のバックグラウンドの減少率が約 $1 / 6$ であまり大きくな い.したがって，波高分析してもしなくても分析法とし て顕著な差がないものと思われる。

終りに臨み御愁切な御指導を賜わった野田稲吉先生に 深謝申し上げます。

（昭和 36 年 4 月 1 日，日本化学会第 14 年会で講演）

\section{交献}

1) 深沢 力, 武内次夫, 一柳昭成：本誌, 10, 1070 (1961).

2) D. J. Dodds, L. C. Von de Veld : Norelco Reporter, 2, 87 (1955).

3) P. H. Dowling, G. F. Hendee, T. R. Kohler, W. Parrish : Philips Tech. Rev., 18, 262 (1956/57).

4) D. C. Miller : Norelco Reporter, 4, 37(1957).

$$
\sum
$$

Determination of cobalt and iron. (X-ray fluorescence analysis of copper-nickel alloy. II.) Tsutomu FuKasawa*, Tsugio TAKEUCHI ${ }^{*}$ and Akinari ICHIRYU** (* Institute of Techno-analytical Chemistry, Faculty of Engineering, Nagoya University and ** Sumitomo Light Metal Industries Co.)

A nondestructive analysis with the measurement of X-ray fluorescence intensity from its spectrum taken on the recording paper has been investigated. Throughout the experiment, the calibration curves were drawn from the X-ray fluorescence intensity and the content of each component.

Determination of cobalt : Independent calibration curve was necessary for estimation of cobalt in cupronickel and of it in monel metal. In case of cupronickel, the intensity was not affected by the difference in the ratio of copper and nickel, and a simple determination of $0.06 \sim 0.34 \%$ of cobalt with an error of $\sigma=0.006 \%$ was possible. In case of monel metal, however, the difference in copper content affected greatly the fluorescence intensity and it was necessary to prepare each calibration curve for each range of copper content of the alloy.

Determination of iron : A simple and rapid determination of iron was possible by using a calibration curve for cupronikel and monel metal. $0.4 \sim 3.3 \%$ of iron could be estimated with an error $\sigma=0.04 \%$, and even below $0.14 \%$ could be estimated an error $\sigma<0.005 \%$.

The limit of determination by use of the recording method was about the same both in the case of cobalt and iron, and seemed to be $0.01 \sim 0.005 \%$. The variation of $\mathrm{X}$-ray fluorescent intensity due to instability of the apparatus was so little that any correction was unnecessary for micro-analysis with sufficient accuracy. In the nondestructive analysis of cobalt and iron, the effect of pulse height analysis was extremely small.

(Received Apr. 26, 1961) 